\title{
Influência das práticas integrativas e complementares durante 0 trabalho de parto: uma revisão integrativa
}

\author{
Influence of integrative and complementary practices during labor: an integrative review \\ Influencia de las prácticas integradoras y complementarias durante el trabajo de parto: \\ una revisión integradora
}

Willyane Beatriz Ximenes de Araújo ${ }^{1 *}$, Sheyla Saionara de Souza Barbosa ${ }^{1}$, Alexandra Maria da Silva $^{1}$, Lúcia Carolina dos Santos ${ }^{1}$, Marcia Gomes Vital da Silva ${ }^{1}$, Ângela Roberta Lessa de Andrade $^{2}$, Hirla Vanessa Soares Araújo², Carmen Daniella Batista de Oliveira ${ }^{3}$.

\section{RESUMO}

Objetivo: Analisar nas atuais evidências científicas como as Práticas Integrativas e Complementares influenciam durante o trabalho de parto e contribuem para a diminuição da dor. Métodos: Revisão integrativa da literatura, na qual foram consultados artigos nas bases de dados, Scielo, Lilacs, Medline e BDEnf, sendo selecionados estudos que se enquadrassem na temática em questão, nos idiomas inglês, português e espanhol, entre os anos de 2016 e 2021. Resultados: Após uma avaliação de estudos da atualidade, verificou-se que as práticas nas quais as gestantes utilizaram, trouxeram alívio da dor e ansiedade no trabalho de parto, dentre as mais utilizadas estão o banho de aspersão com água morna, bola suíça e a presença do acompanhante. Considerações finais: Diante disso, torna-se necessário que os profissionais de saúde utilizem as práticas integrativas e complementares no seu dia-a-dia, esclarecendo seus benefícios as gestantes e oferecendo total autonomia a mulher para escolher o que deseja neste momento único tornandoo mais especial.

Palavras-chave: Terapias complementares, Gravidez, Trabalho de parto, Humanização.

\begin{abstract}
Objective: To analyze in the current scientific evidence how integrative and complementary practices influence during labor and contribute to the reduction of pain. Methods: Integrative literature review, in which articles were consulted in the databases, Scielo, Lilacs, Medline and BDEnf, with studies that is adequate with the theme in question, in English, Portuguese and Spanish, between the years 2016 an 2021. Results: After an evaluation of current studies, verified that the practices in which pregnant women used, brought relief from pain and anxiety in labor, among the most used are the bath with warm water, Swiss ball and companion presence. Final considerations: Therefore, it is necessary that health professionals use integrative and complementary practices in their daily life, clarifying their benefits to pregnant women and offering full autonomy to women to choose what they want in this unique moment, making it more special.
\end{abstract}

Key words: Complementary therapies, Pregnancy, Labor, Humanization.

\section{RESUMEN}

Objetivo: Analizar en la evidencia científica actual cómo las Prácticas Integrativas y complementarias influyen durante el parto y contribuyen a la reducción del dolor. Métodos: Revisión de literatura integradora, en la que se consultaron artículos en las bases de datos, Scielo, Lilacs, Medline y BDEnf, con estudios que se ajustan al tema en cuestión, en inglés, portugués y español, entre los años 2016 y 2021 . Resultados: Luego de una evaluación de los estudios actuales, se encontró que las prácticasus utilizadas por las embarazadas usaban, trajeron alivio del dolor y la ansiedad en el parto, entre las más utilizadas se encuentran el baño de aspersión con agua tibia, pelota suiza y presencia de acompañante. Consideraciones finales: Por ello, es necesario

\footnotetext{
${ }^{1}$ Centro Universitário dos Guararapes (UNIFG), Jaboatão dos Guararapes - PE.

*E-mail: willyanebeatriz97@gmail.com

2 Universidade de Pernambuco (UPE), Recife - PE.

${ }^{3}$ Universidade Federal de Pernambuco (UFPE), Recife - PE.
} 
que los profesionales de la salud adopten utilicen prácticas integradoras y complementarias en su vida diaria, aclarando sus beneficios a las embarazadas y ofreciendo plena autonomía a las mujeres para elegir lo que desean en este momento único, haciéndolo más especial.

Palabras clave: Terapias complementarias, El embarazo, Trabajo de parto, Humanización.

\section{INTRODUÇÃO}

A gestação é um período que as gestantes geram muitas expectativas, proporcionando emoções, tensões, atitudes, experiências e a espera pelo desconhecido tende a provocar transformações em sua vida, gerando medo e incertezas (POSSATI AB, et al., 2017). Para que tudo ocorra com tranquilidade, o apoio familiar durante a gravidez é imprescindível para o binômio mãe e bebê, uma vez que, os sentimentos de risco a saúde estão presentes. Quando o apoio é eficaz, a mulher fica mais tranquila para as futuras mudanças, sem sofrimentos, exigindo menos intervenções médicas, tornando o processo mais prazeroso e saudável (LARA SRG, 2020).

A forma como a gestante é acolhida em sua família, causará diversos sintomas e respostas durante esse período frágil e de transformação. $O$ tratamento do marido para com a gestante contribui para aceitar ou rejeitar sua gravidez e como ela irá vivenciar as modificações deste processo. Acompanhar a mulher durante o trabalho de parto é uma oportunidade para vivenciar o momento mais esperado pela família, o nascimento do bebê. $\mathrm{O}$ apoio recebido neste momento ajuda a mulher a lidar com os sentimentos provocados durante essa fase do parto, trazendo sensações de segurança e apoio, assim se sentindo acompanhada pelos profissionais de saúde e pela família, contribuindo de forma positiva no momento do parto, amamentação, aceitação da gestante com o bebê e responsabilidades impostas pelo pós-parto (AVANZI SA, et al., 2019).

As intervenções e condutas tem o potencial de desqualificar o cuidado fornecido à mulher durante o parto, ignorando seus direitos e de sua família neste processo. Diante disso, a Organização Mundial da Saúde (OMS), o Ministério da Saúde e os Órgãos não governamentais propuseram mudanças que enfatizam o cuidado às mulheres, incluindo o resgate ao parto natural, estimulando enfermeiros obstetras e equipes qualificadas na assistência a gestação e ao parto. A humanização ao parto refere-se a acolher, orientar, ouvir e criar um vínculo, tornando-se aspectos fundamentais no cuidado as mulheres (POSSATI AB, et al., 2017).

De acordo com o Programa Nacional de Humanização do Pré-natal e Nascimento (PHPN), a humanização inclui a aceitação digna da tríade família-mãe-bebê com base no comportamento moral e solidário. Contudo, a instituição deve oferecer um ambiente acolhedor rompendo com o isolamento tradicionalmente proposto às mulheres de forma a abranger o uso de práticas que contribuam com a evolução do parto e nascimento, descartando as medidas intervencionistas que geram riscos à saúde da mãe e do bebê. Para tanto, podem ser utilizadas técnicas não medicamentosas para aliviar a dor, tais como: deambulação e massagem lombar (POSSATI AB, et al., 2017; BRASIL, 2002).

Ressaltando que o parto humanizado não é caracterizado apenas pelo uso das Práticas Integrativas e Complementares em Saúde (PICS), e sim pelo respeito na totalidade da parturiente, participando das decisões do seu atendimento e tornando-se protagonista do seu parto, enquanto o profissional assiste à parturição (OLIVEIRA LLF, et al., 2017).

A maneira como alguns profissionais assistem ao parto levam as mulheres a terem um grande receio na hora de partejar, preferindo uma cesariana a um parto normal. Para que a parturiente seja atendida de forma singular, faz-se necessário adotar medidas humanizadas que melhorem 0 trabalho de parto e consequentemente reduza as experiências negativas, como a dor. Esta, no trabalho de parto, apresenta duas interfaces em seu conceito: uma causada pelas lesões naturais ou potenciais e outra relacionada a experiências emocionais, sensoriais e culturais, tornando a sensação pessoal e subjetiva (SILVA CA, 2018 e LARA SRG, 2020).

As PICS são recursos terapêuticos utilizados na perspectiva de recuperar a saúde e prevenir agravos. Sua utilização envolve escuta ativa e humanizada com vistas ao estabelecimento do vínculo terapêutico entre o 
indivíduo e o meio no qual ele se encontra inserido (BRASIL, 2006). Das PICS disponíveis no Sistema Único de Saúde (SUS) as mais utilizadas durante o trabalho de parto envolvem a aromaterapia, musicoterapia, cromoterapia, banho morno de aspersão, massagem lombar, acupressão, banqueta, cavalinho, exercícios respiratórios, acompanhantes, bola suíça, entre outros (MASCARENHAS VHA, et al., 2019).

Durante o parto as utilizações dessas práticas proporcionam a autoestima, autocuidado e vem atuando como propostas de intervenções para as mulheres no intuito de amenizar os efeitos gestacionais, como a dor, medo e ansiedade, ressaltando o poder da mulher de ser protagonista de seu parto, desenvolvendo habilidades de controle com o seu corpo e sua saúde (SILVA R M, et al., 2016).

A inserção desses métodos não farmacológicos para o alívio da dor são técnicas que necessitam de conhecimento específico para sua aplicação. Os profissionais precisam ter conhecimento das contraindicações das PICS para cada fase da gestação, evitando lesionar o binômio mãe-bebê (FERNANDES KS, et al., 2021).

Quando se trata de Trabalho de Parto (TP), o uso das PICS vem ganhando mais visibilidade tornando a primeira fase do TP, no qual a mulher apresenta contrações contínuas, mais humanizadas, pensando no seu direito de escolha, na totalidade dos benefícios destas práticas para a mãe e bebê, respeitando seus direitos e valorizando o conhecimento popular (SILVA RM, et al., 2016).

A presente revisão integrativa visou analisar o que as evidências científicas apontam sobre como as práticas integrativas e complementares influenciam durante o trabalho de parto e contribuem para a diminuição da dor.

\section{MÉTODOS}

O presente estudo trata-se de uma revisão integrativa da literatura, que consiste em seis fases do seu processo de elaboração: construção da pergunta norteadora, busca na literatura, coleta de dados, análise crítica dos estudos incluídos, resultado e discussão dos artigos (SOUZA MT, et al.,2010).

Após a seleção da temática da influência das práticas integrativas e complementares durante o trabalho de parto, foi definida a seguinte questão norteadora: "O que as evidências científicas apontam sobre como as PICS influenciam durante o trabalho de parto?".

A coleta de dados ocorreu entre os meses de Março e Abril do ano de 2021, foram consultados artigos nas bases de dados: Scientific Electronic Library Online (Scielo), Literatura Latino-Americana e do Caribe em Ciências da Saúde (Lilacs), US National Library of Medicine (MEDLINE) e Base de Dados de Enfermagem (BDENF).

Realizou-se a seleção de descritores após consulta ao Descritores em Ciências da Saúde (DeCS)/ Medical Subject Headings (MeSH). Os descritores utilizados e suas combinações foram: 1) Terapias complementares AND Trabalho de parto; 2) Gravidez AND Humanização; 3) Terapias complementares AND Gravidez; 4) Trabalho de parto AND humanização; 5) Terapias Complementares AND Trabalho de Parto AND Humanização.

Com o objetivo de abranger o maior número de publicações sobre o assunto seguiu-se a mesma sequência ao inserir descritores para busca na base de dados. Desta forma foram encontradas 79 publicações na Scielo, 819 na Lilacs, 462 na Medline e 452 na BDEnf. Após a aplicação dos critérios de inclusão permaneceram 9 publicações na Scielo, 29 na Lilacs, 32 na Medline e 52 na BDEnf, sendo 16 artigos incluídos e 106 excluídos por não abordarem o tema do estudo.

Os critérios de elegibilidade para a inclusão dos artigos na pesquisa foram todos aqueles que trazem informações relevantes sobre as influências das práticas integrativas e complementares durante o trabalho de parto. Foram selecionados todos os que se enquadrassem na temática em questão, publicados entre os anos de 2016 e 2021, nos idiomas inglês, português e espanhol e disponível na íntegra e gratuitamente. Foram excluídos artigos, matérias de revistas e livros completos que não respondessem à questão norteadora do estudo, como demonstrado na Figura 1. 
Figura 1 - Fluxograma com base de dados, seleção, elegibilidade e inclusão de artigos para a revisão integrativa, 2021.
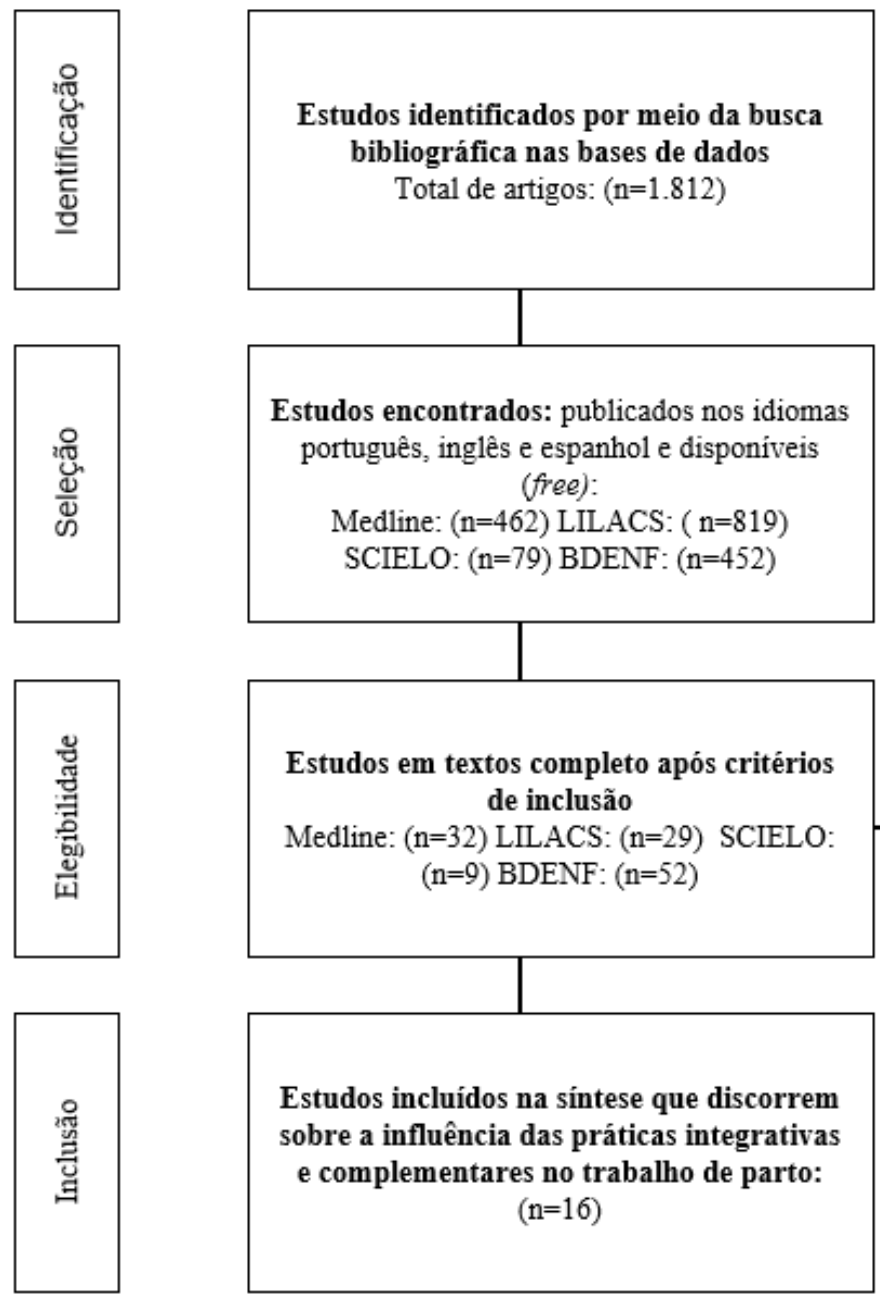

Estudos excluídos pois não abordavam 0 tema estudado: $(\mathrm{n}=106)$

Fonte: Araújo WBX, et al., 2021.

Houve a exclusão dos artigos que não se enquadravam nos critérios descritos, bem como aqueles que após leitura do título e resumo e leitura na íntegra não apresentavam conteúdo relevante para esse estudo. Os artigos duplicados foram registrados apenas uma vez. Em seguida, realizou-se análise detalhada dos artigos, considerando o rigor e as características dos mesmos, seguindo-se ao registro das informações elencadas no instrumento. As informações foram interpretadas, resumidas e organizadas em quadro síntese, comparando-se os resultados, e finalizadas com proposições acerca dos estudos.

\section{RESULTADOS E DISCUSSÃO}

Após leitura e avaliação dos estudos selecionados, obteve-se uma amostra final de 16 artigos para produção desta revisão integrativa. Quanto ao período de publicação, 6 foram publicados em 2019, 3 no ano de 2017, 2 em 2020 e 1 nos anos 2016, 2018 e 2021. Estes foram descritos através dos seus respectivos dados: autores/ano, título do artigo, revista de publicação, idioma e objetivos (Quadro 1).

O Quadro 2 traz a modalidade da pesquisa, nível de evidência e a síntese dos resultados. Destes, 7 apresentam nível de evidência VI, 6 apresentam nível V, 1 apresenta nível IV e 1 de nível VII. 


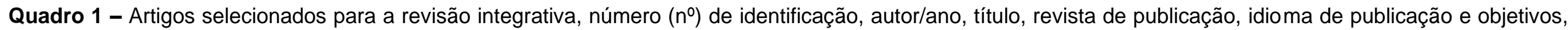
2021.

\begin{tabular}{|c|c|c|c|c|c|}
\hline $\mathbf{N}^{\circ}$ & Autores/Ano & Título do artigo & $\begin{array}{l}\text { Revista de } \\
\text { publicação }\end{array}$ & $\begin{array}{l}\text { Idioma de } \\
\text { publicação }\end{array}$ & Objetivos \\
\hline 1 & $\begin{array}{l}\text { AVANZI SA, et } \\
\text { al., } 2019\end{array}$ & $\begin{array}{l}\text { Importância do apoio familiar no período } \\
\text { gravídico-gestacional sob a perspectiva } \\
\text { de Gestantes inseridas no PHPN. }\end{array}$ & $\begin{array}{l}\text { Revista de Saúde } \\
\text { Coletiva da UEFS }\end{array}$ & Português & $\begin{array}{c}\text { Analisar a percepção de gestantes sobre a } \\
\text { importância do apoio familiar no período gravídico- } \\
\text { gestacional. }\end{array}$ \\
\hline 2 & $\begin{array}{l}\text { POSSATI AB, et } \\
\text { al., } 2017\end{array}$ & $\begin{array}{l}\text { Humanization of childbirth: meanings } \\
\text { and perceptions of nurses. }\end{array}$ & Escola Anna Nery & Inglês & $\begin{array}{c}\text { Conhecer os significados atribuídos ao parto } \\
\text { humanizado por enfermeiras de um centro } \\
\text { obstétrico. }\end{array}$ \\
\hline 3 & $\begin{array}{l}\text { SILVA CA, et al, } \\
2019 .\end{array}$ & $\begin{array}{l}\text { Use of the shower aspersion combined } \\
\text { with the swiss ball as a method of pain } \\
\text { relief in the active labor stage. }\end{array}$ & $\begin{array}{l}\text { Brazilian Journal of } \\
\text { Pain (BrJP) }\end{array}$ & Inglês & $\begin{array}{l}\text { Correlacionar a eficácia da associação do banho de } \\
\text { aspersão e da bola suíça como formas de alívio da } \\
\text { dor na fase ativa do trabalho de parto. }\end{array}$ \\
\hline 4 & $\begin{array}{l}\text { SILVA ALA, et al., } \\
\qquad 2017\end{array}$ & $\begin{array}{l}\text { A qualidade do atendimento ao parto na } \\
\text { rede pública hospitalar em uma capital } \\
\text { brasileira: a satisfação das gestantes. }\end{array}$ & $\begin{array}{l}\text { Cad. Saúde } \\
\text { Pública/RJ }\end{array}$ & Português & $\begin{array}{l}\text { Avaliar a qualidade da atenção ao parto na rede } \\
\text { pública hospitalar, na cidade do Recife, Pernambuco, } \\
\text { Brasil, segundo satisfação das gestantes. }\end{array}$ \\
\hline 5 & $\begin{array}{l}\text { SILVA RM, et al., } \\
\qquad 2016\end{array}$ & $\begin{array}{c}\text { Uso de práticas integrativas e } \\
\text { complementares por doulas em } \\
\text { maternidades de Fortaleza (CE) e } \\
\text { Campinas (SP). }\end{array}$ & Saúde e Sociedade & Português & $\begin{array}{c}\text { Analisar as Práticas Integrativas e Complementares } \\
\text { (pics) utilizadas por doulas nos municípios de } \\
\text { Fortaleza (CE) e Campinas (SP). }\end{array}$ \\
\hline 6 & $\begin{array}{l}\text { FERNANDES KS, } \\
\quad \text { et al., } 2021\end{array}$ & $\begin{array}{l}\text { Use of Integrative and Complementary } \\
\text { Health Practices by professionals in } \\
\text { pregnant women with low back pain: } \\
\text { integrative review. }\end{array}$ & $\begin{array}{l}\text { Brazilian Journal of } \\
\text { Pain (BrJP) }\end{array}$ & Inglês & $\begin{array}{l}\text { Analisar na literatura Nacional e internacional o uso } \\
\text { das práticas integrativas e complementares em } \\
\text { saúde pelos profissionais em gestantes com dores } \\
\text { lombares. }\end{array}$ \\
\hline 7 & $\begin{array}{l}\text { COELHO KC, et } \\
\text { al., } 2018\end{array}$ & $\begin{array}{l}\text { Métodos não farmacológicos para alívio } \\
\text { da dor durante o trabalho de parto. }\end{array}$ & $\begin{array}{l}\text { Revista Cientifica de } \\
\text { Enfermagem }\end{array}$ & Português & $\begin{array}{c}\text { Verificar quais são os métodos não farmacológicos } \\
\text { mais utilizados para o alívio da dor durante o } \\
\text { trabalho de parto. }\end{array}$ \\
\hline 8 & $\begin{array}{l}\text { DE LARA SRG, et } \\
\text { al., } 2020\end{array}$ & $\begin{array}{l}\text { Experience of women in labor with the } \\
\text { use of flowers essences. }\end{array}$ & $\begin{array}{l}\text { Revista de Pesquisa: } \\
\text { Cuidado é } \\
\text { Fundamental Online }\end{array}$ & Inglês & $\begin{array}{c}\text { Descrever a vivência de mulheres submetidas ao } \\
\text { uso de essências florais como terapia não } \\
\text { farmacológica para o alívio da dor e ansiedade } \\
\text { durante o trabalho de parto. }\end{array}$ \\
\hline
\end{tabular}




\begin{tabular}{|c|c|c|c|c|c|}
\hline $\mathbf{N}^{\circ}$ & Autores/Ano & Título do artigo & $\begin{array}{l}\text { Revista de } \\
\text { publicação }\end{array}$ & $\begin{array}{l}\text { Idioma de } \\
\text { publicação }\end{array}$ & Objetivos \\
\hline 9 & $\begin{array}{l}\text { OLIVEIRA LLF, et } \\
\text { al., } 2017\end{array}$ & $\begin{array}{l}\text { As vivências de conforto e desconforto } \\
\text { da mulher durante o trabalho de parto. }\end{array}$ & $\begin{array}{l}\text { Revista Enfermagem } \\
\text { UERJ }\end{array}$ & Português & $\begin{array}{c}\text { Analisar as vivências de conforto e desconforto da } \\
\text { mulher durante o trabalho de parto e parto. }\end{array}$ \\
\hline 10 & BRASIL, 2006 & Portaria n 971, de 03 de maio de 2006. & $\begin{array}{l}\text { Biblioteca Virtual em } \\
\text { Saúde MS }\end{array}$ & Português & $\begin{array}{l}\text { Política de caráter nacional, recomenda a adoção } \\
\text { pelas Secretarias de Saúde dos Estados, do Distrito } \\
\text { Federal e dos Municípios, da implantação e } \\
\text { implementação das ações e serviços relativos às } \\
\text { Práticas Integrativas e complementares. }\end{array}$ \\
\hline 11 & $\begin{array}{l}\text { CAVALCANTI } \\
\text { ACV, et al., } 2019\end{array}$ & $\begin{array}{l}\text { Terapias complementares no trabalho } \\
\text { de parto: ensaio clínico randomizado. }\end{array}$ & $\begin{array}{l}\text { Revista Gaúcha de } \\
\text { Enfermagem }\end{array}$ & Português & $\begin{array}{l}\text { Avaliar o efeito do banho quente de chuveiro e } \\
\text { exercício perineal com bola suíça isolada e de forma } \\
\text { combinada, sobre a percepção da dor, ansiedade e } \\
\text { progressão do trabalho de parto. }\end{array}$ \\
\hline 12 & $\begin{array}{l}\text { FERREIRA MC, } \\
\text { et al., } 2019 .\end{array}$ & $\begin{array}{l}\text { Percepções de profissionais de } \\
\text { enfermagem sobre humanização do } \\
\text { parto em ambiente hospitalar. }\end{array}$ & Revista Rene & Português & $\begin{array}{l}\text { Compreender as percepções de profissionais de } \\
\text { enfermagem quanto à humanização do parto. }\end{array}$ \\
\hline 13 & $\begin{array}{l}\text { MASCARENHAS } \\
\text { VHA, et al., } 2019\end{array}$ & $\begin{array}{l}\text { Evidências científicas sobre métodos } \\
\text { não farmacológicos para alívio a dor do } \\
\text { parto. }\end{array}$ & $\begin{array}{l}\text { Acta Paulista de } \\
\text { Enfermagem }\end{array}$ & Português & $\begin{array}{l}\text { Identificar na literatura nacional e internacional, } \\
\text { estudos sobre a eficácia de métodos não } \\
\text { farmacológicos na redução da dor do parto. }\end{array}$ \\
\hline 14 & $\begin{array}{l}\text { SILVA MA, et al., } \\
\qquad 2019\end{array}$ & $\begin{array}{l}\text { Aromaterapia para alívio da dor durante } \\
\text { o trabalho de parto. }\end{array}$ & $\begin{array}{l}\text { Revista Enfermagem } \\
\text { UFPE }\end{array}$ & Português & $\begin{array}{c}\text { Analisar a utilização da aromaterapia no alívio da dor } \\
\text { durante o trabalho de parto. }\end{array}$ \\
\hline 15 & $\begin{array}{l}\text { SILVA GK, et al., } \\
\qquad 2020\end{array}$ & $\begin{array}{l}\text { Política Nacional de Práticas } \\
\text { Integrativas e Complementares: } \\
\text { trajetória e desafios em } 30 \text { anos do } \\
\text { SUS. }\end{array}$ & $\begin{array}{l}\text { Physis: Revista de } \\
\text { Saúde Coletiva }\end{array}$ & Português & $\begin{array}{l}\text { Analisar a construção e desenvolvimento da Política } \\
\text { Nacional de Práticas Integrativas e Complementares } \\
\text { (PNPIC) no SUS e seus antecedentes. }\end{array}$ \\
\hline 16 & BRASIL, 2002. & $\begin{array}{l}\text { Programa de Humanização no Pré-natal } \\
\text { e Nascimento }\end{array}$ & $\begin{array}{l}\text { Biblioteca Virtual em } \\
\text { Saúde MS }\end{array}$ & Português & $\begin{array}{l}\text { Assegurar a melhoria do acesso, da cobertura e da } \\
\text { qualidade do acompanhamento pré-natal, da } \\
\text { assistência ao parto e puerpério às gestantes e ao } \\
\text { recém-nascido, na perspectiva dos direitos de } \\
\text { cidadania. }\end{array}$ \\
\hline
\end{tabular}

Fonte: Araújo WBX, et al., 2021. 
Quadro 2 - Número (nº) de identificação, modalidade da pesquisa, nível de evidência e a síntese dos resultados dos artigos selecionados para a revisão integrativa, 2021

\begin{tabular}{|c|c|c|c|}
\hline $\mathbf{N}^{\circ}$ & Modalidade da Pesquisa & Nível de Evidência & Síntese dos Resultados \\
\hline 1 & $\begin{array}{l}\text { Estudo observacional, } \\
\text { descritivo, quantiqualitativo. }\end{array}$ & Nível VI & $\begin{array}{l}\text { É importante que a gestante se sinta apoiada e segura para dar continuidade às tarefas que já } \\
\text { estavam presentes em sua rotina antes da gravidez, contribuindo para o processo de adesão ao } \\
\text { pré-natal e posteriormente nos cuidados com o bebê. }\end{array}$ \\
\hline 2 & Pesquisa qualitativa descritiva. & Nível VI & $\begin{array}{l}\text { A humanização do parto foi compreendida como um conjunto de práticas e atitudes pautadas no } \\
\text { diálogo, empatia e acolhimento; o fornecimento de orientações e a realização de procedimentos } \\
\text { comprovadamente benéficos à saúde materno-infantil. }\end{array}$ \\
\hline 3 & Revisão integrativa & Nível V & $\begin{array}{l}\text { Redução significativa do escore de dor quando associadas ambas as terapêuticas, banho de } \\
\text { aspersão e bola suíça na fase ativa, além de atuar de modo efetivo na progressão do trabalho de } \\
\text { parto. }\end{array}$ \\
\hline 4 & $\begin{array}{l}\text { Estudo quantitativo transversal, } \\
\text { de cunho exploratório. }\end{array}$ & Nível VI & $\begin{array}{l}\text { Os resultados apontam para avanços na prestação dos cuidados às gestantes e puérperas, o } \\
\text { desenvolvimento de práticas recomendadas pelo modelo humanístico de atenção ao parto, } \\
\text { consolidação do acolhimento, e do vínculo entre profissionais e usuárias no sentido do respeito, } \\
\text { dignidade e cortesia. }\end{array}$ \\
\hline 5 & $\begin{array}{l}\text { Relato de uma pesquisa } \\
\text { qualitativa }\end{array}$ & Nível VI & $\begin{array}{l}\text { O espaço de atuação das doulas se vinculou ao uso da Medicina Tradicional, identificada no } \\
\text { campo das recomendações e usos durante a gestação e o parto. As entrevistadas acreditam que } \\
\text { a utilização das práticas pode promover a sensibilização da gestante para um modelo mais } \\
\text { humanizado. }\end{array}$ \\
\hline 6 & Revisão integrativa & Nível V & $\begin{array}{l}\text { A utilização das Práticas Integrativas e Complementares em Saúde pelos profissionais pode } \\
\text { proporcionar novas oportunidades, maior conhecimento, melhor assistência às gestantes, } \\
\text { satisfação e bem-estar durante a gestação. }\end{array}$ \\
\hline 7 & $\begin{array}{l}\text { Revisão narrativa da } \\
\text { bibliografia. }\end{array}$ & Nível V & $\begin{array}{l}\text { Ficaram evidentes os benefícios dos métodos não farmacológicos utilizados durante o trabalho } \\
\text { de parto e sua eficácia. }\end{array}$ \\
\hline 8 & $\begin{array}{l}\text { Pesquisa descritiva } \\
\text { Exploratória, de conteúdo } \\
\text { qualitativo. }\end{array}$ & Nível VI & $\begin{array}{l}\text { Os efeitos da terapia floral atuaram em sinergia, na redução dos sintomas de estresse-medo- } \\
\text { tensão, além do aumento do bem-estar emocional proporcionando a oportunidade de protagonizar } \\
\text { o seu próprio trabalho de parto e parto. }\end{array}$ \\
\hline 9 & Estudo descritivo qualitativo & Nível VI & $\begin{array}{l}\text { O nascimento do filho, a assistência dos profissionais, o acompanhante, a dor, a episiorrafia e o } \\
\text { aumento das dores devido ao uso do "soro" estão entre as principais vivências de conforto e } \\
\text { desconforto relatadas. }\end{array}$ \\
\hline
\end{tabular}




\begin{tabular}{|c|c|c|c|}
\hline $\mathbf{N}^{\circ}$ & Modalidade da Pesquisa & Nível de Evidência & Síntese dos Resultados \\
\hline 10 & Portaria - Ministério da Saúde. & Nível VII & $\begin{array}{l}\text { Aprovação da Política Nacional de Práticas Integrativas e Complementares (PNPIC) no Sistema } \\
\text { Único de Saúde (SUS). }\end{array}$ \\
\hline 11 & $\begin{array}{l}\text { Ensaio clínico randomizado e } \\
\text { controlado }\end{array}$ & Nível IV & $\begin{array}{l}\text { Houve aumento no escore de dor e redução da ansiedade em todos os grupos, sobretudo quando } \\
\text { utilizaram banho de chuveiro. A dilatação cervical bem como o número de contrações uterinas } \\
\text { também aumentou em todos os grupos. }\end{array}$ \\
\hline 12 & Pesquisa qualitativa & Nível VI & $\begin{array}{l}\text { Os profissionais ressaltaram as ações realizadas que refletem na humanização do parto, mas } \\
\text { destacaram as dificuldades às questões estruturais e de recursos que refletem negativamente na } \\
\text { qualidade da assistência prestada. }\end{array}$ \\
\hline 13 & Revisão integrativa & Nível V & $\begin{array}{l}\text { Dentre os métodos não farmacológicos encontrados, destacam-se: a acupuntura e suas principais } \\
\text { variações, hidroterapia, exercícios perineais com a bola suíça e terapias térmicas. }\end{array}$ \\
\hline 14 & $\begin{array}{l}\text { Estudo bibliográfico, descritivo, } \\
\text { do tipo revisão integrativo. }\end{array}$ & Nível V & $\begin{array}{l}\text { A aromaterapia possui um leque de variedades com propriedades específicas, é um método } \\
\text { excelente para o alívio da dor e/ou diminuição da ansiedade e medo, auxilia na contração e } \\
\text { redução do tempo de trabalho de parto. }\end{array}$ \\
\hline 15 & $\begin{array}{l}\text { Revisão de literatura, análise } \\
\text { documental e entrevistas. }\end{array}$ & Nível V & $\begin{array}{l}\text { Influência de parâmetros internacionais, papel das conferências nacionais de saúde na construção } \\
\text { da demanda social, protagonismo no âmbito do ensino e pesquisa, entrada na agenda política, } \\
\text { condução federal e desafios para a institucionalização. }\end{array}$ \\
\hline 16 & Portaria - Ministério da Saúde. & Nível VII & $\begin{array}{l}\text { Redução das altas taxas de morbimortalidade materna, peri e neonatal, adoção de medidas que } \\
\text { assegurem a melhoria do acesso e da qualidade do acompanhamento pré-natal, ao parto, } \\
\text { puerpério e neonatal. }\end{array}$ \\
\hline
\end{tabular}

Fonte: Araújo WBX, et al., 2021. 
A gestação além de ser um processo fisiológico normal na vida da mulher ocasiona modificações físicas e psicológicas durante seu desenvolvimento, gerando medo e desconforto que podem afetar a gravidez positiva ou negativamente. Essas mudanças geram reflexões sobre aspectos psicológicos na vida das mulheres e exigem necessidades de afeto, carinho, cuidado e proteção. Isso é necessário para a equipe de saúde entender e identificar a angústia e as modificações vivenciadas por mulheres grávidas, de modo que ao longo do serviço, se sintam seguras e preparadas para o durante e o pós-período gestacional (COELHO KC, 2018; AVANZI AS, et al., 2019).

Segundo o estudo sobre a importância do apoio familiar no ciclo gravídico-puerperal há a necessidade da participação da família durante a gestação para amenizar o medo e a insegurança que a gestante apresenta neste processo (AVANZI SA, et al., 2019). Diante dos significados atribuídos ao parto humanizado, enfermeiras de um centro obstétrico corroboram trazendo o conceito de humanização do parto como um movimento individual e singular, valorizando o protagonismo da mulher e permitindo uma concordância do cuidado com a cultura, crenças e valores, propiciando a mulher o direito de ser mãe com respeito, solidariedade e amor (POSSATI AB, et al., 2017).

A presença do acompanhante durante o trabalho de parto e parto no âmbito do SUS é aprovado pela lei 11.108/2005 como uma prática contribuinte para humanização do parto. A presença fornecida pelo acompanhante causa encorajamento e conforto, consequentemente reduzindo os níveis de estresse, ansiedade e principalmente o sentimento de solidão (OLIVEIRA LLF, et al., 2017). É natural que a gestante sinta dor durante o trabalho de parto, o que pode interferir em suas funções fisiológicas. Para melhorar a evolução da parturição e reduzir os efeitos adversos adotando medidas humanizadas surgiu a Política Nacional de Práticas Integrativas e Complementares (PNPIC). Durante o trabalho de parto as mulheres referem sentir dor e, com o intuito de reduzir a utilização dos métodos farmacológicos, adotou-se a utilização de recursos terapêuticos, como banho de aspersão, bola suíça, aromaterapia, entre outros (SILVA GKF, et al., 2020, SILVA CA e LARA SRG, 2018; FERREIRA MC, et al., 2019).

Em 2016, foi realizada um estudo sobre a prática de métodos não medicamentosos para o alívio da dor do parto. A pesquisa descreveu quais métodos não farmacológicos são mais conhecidos por puérperas durante o TP, dentre eles os mais citados foram banho morno e deambulação $(83,1 \%$ e $81,4 \%$ respectivamente). O banho foi de maior aceitação com $(66,6 \%)$ e a maioria das mulheres considerou que esse método foi benéfico, pois quando a água morna é aplicada sobre o dorso, alivia a lombalgia e diminui a sensação dolorosa da parturição (SILVA CA e LARA SRG, 2018; MIELKE KC, et al., 2019).

No entanto, o artigo sobre terapias complementares no TP avaliou os efeitos do banho quente de chuveiro e o uso de bola suíça para exercícios perineais, isoladamente e em combinação, foi descoberto em seu estudo que as mulheres que receberam banho de aspersão isoladamente, aumentaram o nível de dor, embora esse aumento tenha sido bem aceito em termos de diminuição do tempo do trabalho de parto ao nascimento, especialmente quando usadas em conjunto (CAVALCANTI ACV, et al., 2019).

Segundo Silva CA e Lara SRG (2018) a utilização da bola suíça também é um dos métodos mais utilizados durante o trabalho de parto, estimulando a movimentação da parturiente, permitindo molejo da pelve e agachamento pela utilização na posição sentada. Corroborando com esse estudo, Coelho KC (2017) relata que os movimentos realizados com a bola suíça facilitam a descida e rotação do feto, podendo reduzir 0 tempo expulsivo e intensidade da dor referida.

$\mathrm{Na}$ análise da musicoterapia, as evidências científicas sobre métodos não farmacológicos para alívio a dor do parto, relatam um efeito analgésico positivo em parturientes, principalmente nas primigestas, provocando relaxamento com sons de piano e ondas do mar a fim de acalmá-las. Este método comprova que parte da dor sentida durante o trabalho de parto é de princípios subjetivos como ansiedade e medo. As mães que utilizaram a música relataram relaxamento, confiança e redução da dor e dentre as músicas mais pedidas pelas parturientes estão as religiosas e animadas (MASCARENHAS VHA, et al., 2019).

Dentre as práticas terapêuticas, a aromaterapia consiste na utilização de óleos essenciais que evaporam rapidamente estimulando as células nervosas olfativas com ativação do sistema límbico, responsável pela 
memória, olfação e emoção, com influência na frequência cardíaca, estresse e respiração. A aromaterapia utilizada em gestantes, na técnica de inalação, obteve redução da dor, ansiedade e medo (SILVA MA, et al., 2019). Fernandes KC (2021) em seus resultados mostra que não há pesquisas sobre dados específicos da aromaterapia para gestantes com lombalgia. No entanto, ela concluiu que devido a sua ação antinociceptiva pode reduzir a dor lombar e promover efeitos ansiolíticos, deve ser recomendado durante a gravidez, especialmente no final da gestação.

Um estudo com parturientes que utilizaram a aromaterapia durante o trabalho de parto com lavanda em uma combinação de $0,1 \mathrm{ml}$ de óleo de lavanda com $1 \mathrm{ml}$ de água destilada colocado próximo a suas narinas, trouxe como resposta que apesar da redução da dor a aromaterapia não teve influência sobre a duração do TP (MASCARENHAS VHA, et al., 2019). Salienta-se que a utilização da Terapia Floral auxilia no relaxamento e pensamentos positivos, incluindo a ansiedade e estresse. As gestantes protagonizam suas histórias, ficam mais confiantes durante sua evolução do trabalho de parto, calmas e corajosas diante das contrações (LARA SRG, et al., 2020).

A deambulação é uma das práticas mais utilizadas pelas parturientes, é uma técnica simples sem necessidade de recursos para realizá-la, acelera o trabalho de parto pela verticalização, ação da gravidade e mobilidade pélvica que proporcionam o aumento da dilatação uterina e descida do feto (COELHO KC, 2018). Possati AB (2017) por sua vez reforça que a deambulação, além de não oferecer riscos obstétricos, reduz 0 processo do parto e diminui a necessidade de utilização farmacológica.

De acordo com Silva RM, et al. (2016) outro fator contribuinte para tornar esse momento da parturição mais tranquilo para as gestantes é a confiança depositada na equipe de profissionais. $O$ trabalho das doulas contribui para tornar o ambiente do parto mais natural mediante o uso das PICS. Sua atuação é importante para orientar a gestante quanto às etapas da parturição tornando esse momento mais humanizado e respeitando o binômio mãe-bebê. Silva ALA (2017) avaliou em seu estudo que o respeito à gestante demonstrou alta satisfação no atendimento as suas necessidades, consequentemente a redução da dor e ansiedade.

\section{CONSIDERAÇÕES FINAIS}

Após avaliação dos estudos e literatura foi possível verificar que a utilização das PICS pelas gestantes trouxe efeitos positivos para alívio da dor e ansiedade durante o trabalho de parto diminuindo a utilização de fármacos desnecessários. Nesse sentido, é importante informar às gestantes e seus acompanhantes os benefícios e as estratégias que a instituição disponibiliza para escolha em conjunto do melhor método, tornando este momento mais especial, bem como estimular os profissionais da Atenção Primária à Saúde e maternidades à prática das PICS hegemonicamente em todas as unidades e a todos os partos.

\section{REFERÊNCIAS}

1. AVANZI SA, et al. Importância do apoio familiar no período gravídico-gestacional sob a perspectiva de gestantes inseridas no PHPN. Revista de Saúde Coletiva, 2019; 9: 55-62.

2. BRASIL. Manual do Ministério de Saúde. 2002. Disponível em: http://bvsms.saude.gov.br/bvs/publicacoes/parto.pdf. Acessado em: 27 de março de 2021.

3. BRASIL. Ministério da Saúde. Gabinete do Ministro. Portaria n 971, de 3 de maio de 2006. Brasília, 2006. Disponível em: https://bvsms.saude.gov.br/bvs/saudelegis/gm/2006/prt0971_03_05_2006. Acessado em: 27 de março de 2021.

4. CAVALCANTI ACV, et al. Terapias complementares no trabalho de parto: ensaio clínico randomizado. Revista Gaúcha de Enfermagem, 2019; 40.

5. COELHO KC, et al. Métodos não farmacológicos para alívio da dor durante trabalho de parto. Revista Cientifica de Enfermagem, 2018; 8:22.

6. DE LARA SRG, et al. Experience of women in labor with the use of flowers essences / Vivência de mulheres em trabalho de parto com o uso de essências florais. Revista Cuidado é Fundamental Online, 2020; 12: 162-168.

7. FERNANDES KS, et al. Use of Integrative and Complementary Health Practices by professionals in pregnant women with low back pain: integrative review. BrJP [online], 2021; 4:2.

8. FERREIRA MC, et al. Percepções de profissionais de enfermagem sobre humanização do parto em ambiente hospitalar. Rev. Rene, 2019; 20. 
9. MASCARENHAS VHA, et al. Evidências científicas sobre métodos não farmacológicos para alívio a dor do parto. Acta Paul. Enferm, 2019; 32(3): 350-357.

10. MIELKE KC, et al. A prática de métodos não farmacológicos para o alívio da dor de parto em um hospital universitário no Brasil. Av.Enferm, 2019; 37(1): 47-55.

11. OLIVEIRA LLF, et al. As vivências de conforto e desconforto da mulher durante o trabalho de parto. Revista Enfermagem UERJ, 2017; 25.

12. POSSATI AB, et al. Humanização do parto: significados e percepções de enfermeiras. Escola Anna Nery, 2017; 21(4): 1-6.

13. SILVA ALA, et al. A qualidade do atendimento ao parto na rede pública hospitalar em uma capital brasileira: a satisfação das gestantes. Caderno Saúde Pública, 2017; 33(12): e00175116.

14. SILVA CA, LARA SRG. Uso do banho aspersão associado à bola suíça como método de alívio da dor na fase ativa do trabalho de parto. BrJp [online], 2018; 1(2): 167-170.

15. SILVA GKF, et al. Política Nacional de Práticas Integrativas e Complementares: trajetória e desafios em 30 anos do SUS. Physis, 2020; 30(1).

16. SILVA MA, et al. Aromaterapia para alívio da dor durante o trabalho de parto. Revista de Enfermagem UFPE online, 2019; 13(2): 455-463.

17. SILVA RM, et al. Uso de práticas integrativas e complementares por doulas em maternidades de Fortaleza (CE) e Campinas (SP). Saúde soc, 2016; 25(1): 108-120.

18. SOUZA MT, et al. Integrative review: what is it? How to do it?. Einstein, 2010; 8(1). 